\title{
CFD Application to Hydrogen Risk Analysis and PAR Qualification
}

\author{
Jinbiao Xiong, Yanhua Yang, and Xu Cheng \\ School of Nuclear Science and Engineering, Shanghai Jiao Tong University, No. 800 Dongchuan Road, Shanghai 200240, China \\ Correspondence should be addressed to Jinbiao Xiong, superbear@sjtu.edu.cn
}

Received 19 September 2008; Revised 30 November 2008; Accepted 15 January 2009

Recommended by Walter Ambrosini

\begin{abstract}
A three dimensional computation fluid dynamics (CFD) code, GASFLOW, is applied to analyze the hydrogen risk for Qinshan-II nuclear power plant (NPP). In this paper, the effect of spray modes on hydrogen risk in the containment during a large break loss of coolant accident (LBLOCA) is analyzed by selecting three different spray strategies, that is, without spray, with direct spray and with both direct and recirculation spray. A strong effect of spray modes on hydrogen distribution is observed. However, the efficiency of the passive auto-catalytic recombiners (PAR) is not substantially affected by spray modes. The hydrogen risk is significantly increased by the direct spray, while the recirculation spray has minor effect on it. In order to simulate more precisely the processes involved in the PAR operation, a new PAR model is developed using CFD approach. The validation shows that the results obtained by the model agree well with the experimental results.
\end{abstract}

Copyright (C) 2009 Jinbiao Xiong et al. This is an open access article distributed under the Creative Commons Attribution License, which permits unrestricted use, distribution, and reproduction in any medium, provided the original work is properly cited.

\section{Introduction}

During severe accidents, hydrogen can be generated in watercooled reactors by metal-steam reaction. Hydrogen which is released into the containment may form combustible or even detonable gas mixture in the containment. As one of the mitigation measures against severe accidents in the QinshanII NPP, the containment spray system which starts when the containment pressure reaches the threshold value is utilized to prevent the containment overpressure. In the viewpoint of hydrogen risk, the spray operation is concerned due to two aspects. In one respect, the condensation introduced by the operation of the containment spray reduces the steam concentration, which leads to an increase of the hydrogen concentration and adds to the hydrogen combustion or detonation risk. In the other respect, the containment spray brings a gas temperature difference in the containment which promotes the gas mixing and leads to a more uniform distribution of the gas concentration. In this paper, a threedimensional CFD code GASFLOW [1] is utilized to simulate the gas mixing and distribution in the LBLOCA and to evaluate the effect of the containment spray on the hydrogen risk. The case assuming no activation of the containment spray is selected as the base case. Two other cases assuming different containment spray operation strategies are involved in this paper. One of the spray cases considers only the direct spray (indicated as Case A, hereafter), while the other simulates the complete spray operation according to the design of the containment spray system, which includes the direct and recirculation spray (indicated as Case B, hereafter). The same source term is used in all the cases.

As one of the major hydrogen mitigation measures, the passive autocatalytic recombiner (PAR) has been widely used in nuclear power plants. In most studies presented in open literatures, including lumped parameter code analysis and CFD code analysis, the PAR is simply simulated by introducing energy and mass source terms obtained from empirical correlations. According to the state-of-art report on PAR proposed by the PARSOAR project [2], a theoretical PAR model is recommended for the CFD analysis codes, such as GASFLOW, TONUS. In this paper, a PAR model is developed based on the CFD approach, in order to provide more insight into the processes inside a PAR. 


\section{Hydrogen Risk Analysis for Qinshan-II NPP}

2.1. Containment Geometry and Mitigation Systems. The containment of Qinshan-II NPP is a large dry containment which consists of a cylindrical part and a spherical dome, as indicated in Figure 1. The height of the containment is about $60 \mathrm{~m}$, and the diameter is about $38 \mathrm{~m} \mathrm{[3].} \mathrm{The}$ compartments are mainly located below the operation deck at the height of $20 \mathrm{~m}$. The main components of two primary loops are symmetrically arranged in the containment. The deck at the height of $4.5 \mathrm{~m}$ supports the major heavy components including the steam generators (SGs), the reactor coolant pumps (RCPs) and the safety injection tanks (SITs). Similar to most of the pressurized water reactor (PWR), the pressurizer (PZR) is located in a room next to one of the SG towers. The bottom of the PZR room is at a height of about $11 \mathrm{~m}$. The PZR relief tank room is located on the 0 meter floor and right under the PZR room. The refueling pool is from 6 to $20 \mathrm{~m}$ in height. It connects with the reactor cavity in the center of the containment and reaches the containment wall. There are other small rooms accommodating the valve, piping, and heat exchangers on the 0 meter floor and the underground floor. All the abovementioned rooms are located inside a cylindrical missile shielding wall which protects the containment from ejected missiles. The space above the operation deck is much opener. Only the SG towers and the PZR room extend beyond the deck. moreover, in the dome a crane is installed. GASFLOW can generate structural mesh in both Cartesian and cylindrical coordinates. According to the characteristics of the containment geometry, the cylindrical coordinate is selected. The mesh size is adjusted according to the location of the structures in the containment so that the geometry can be described with a coarser mesh system without increasing the computation cost. In the mesh system 18, 60, and 51 cells are, respectively, arranged in radial, circumferential, and axial directions. The free volume of the containment is about $50000 \mathrm{~m}^{3}$. The average cell volume is about $1.4 \mathrm{~m}^{3}$. The total wall surface area is about $24000 \mathrm{~m}^{2}$, most of which is considered as concrete. The components in the primary loop are treated as adiabatic because the adiabatic layer is utilized on them. In order to mitigate the hydrogen risk during severe accidents, 22 passive autocatalytic recombiners (PAR) of Siemens type are installed in the Qinshan-II NPP containment compartments. Table 1 lists the position and type of the PAR. Each PAR is simulated with a single mesh cell.

In Qinshan-II NPP, two separated containment spray systems are installed. According to the design of the spray systems, the containment can be depressurized with only one of them during the severe accidents. Each system includes two nozzle rings, as shown in Figure 2, on which about 250 nozzles are attached. The mass flow is uniformly distributed to every nozzle. Heat exchangers in the system control the temperature of spray water. The spray systems are designed to operate in two modes: direct spray mode and recirculation spray mode. The direct spray starts while the pressure in the containment reaches 2.36 bar. During the direct spray, the spray water comes from the refueling tank, and the

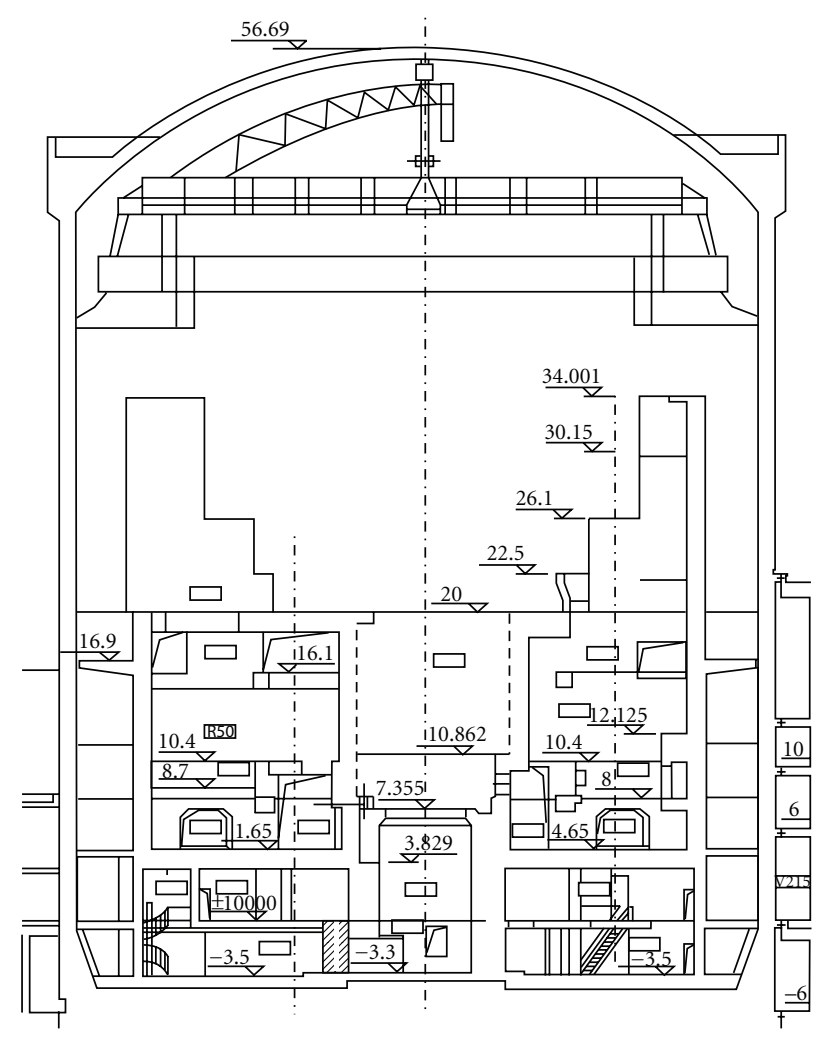

Figure 1: Vertical view of Qinshan-II containment geometry.

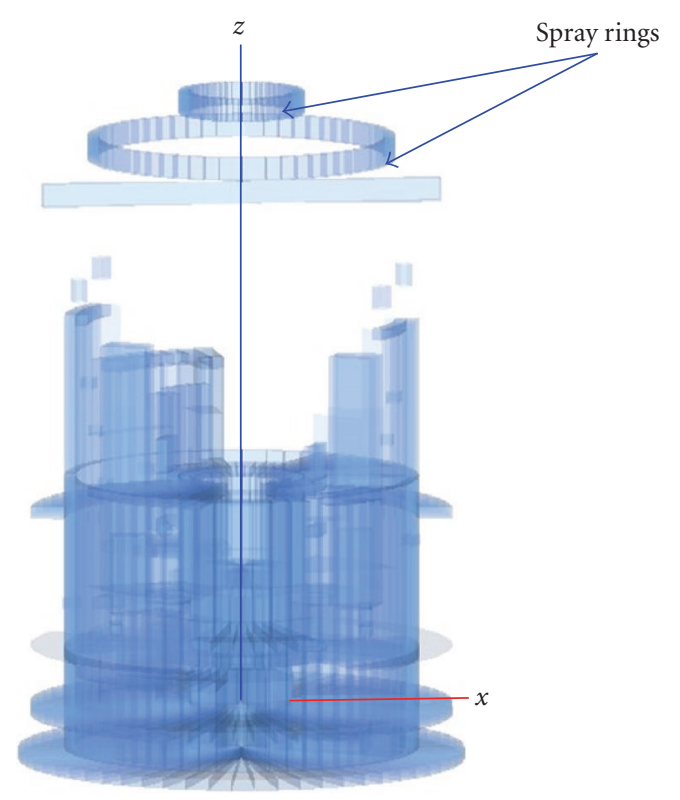

Figure 2: Containment geometry model.

temperature at the nozzle outlet is in the range from 20 to $40^{\circ} \mathrm{C}$. In this paper, the temperature of spray water is given to be $27^{\circ} \mathrm{C}$. In about 30 minutes, the water in the refueling tank will be used up. Then the spray switches to the recirculation mode. In the recirculation mode, the spray water is pumped from the water sump in the containment. Because the water 
TABLE 1: Arrangement of recombiners.

\begin{tabular}{lcc}
\hline Location & Type & No. \\
\hline PZR relief tank room & FR90/1-1500 & 3 \\
Surge line room & FR90/1-960 & 1 \\
PZR room & FR90/1-960 & 1 \\
No. 1 SG compartment & FR90/1-1500 & 3 \\
No. 2 SG compartment & FR90/1-1500 & 3 \\
No.1 RCP room & FR90/1-960 & 1 \\
No.1 RCP room & FR90/1-960 & 1 \\
SIT room & FR90/1-960 & 1 \\
Dome region & FR90/1-1500 & 4 \\
Annular compartment & FR90/1-1500 & 4 \\
\hline
\end{tabular}

in the sump originally comes from the primary loop or the spray water and is at a high temperature, the temperature of the recirculation spray water is higher and is designed to be from 40 to $120^{\circ} \mathrm{C}$. In this paper, the water temperature of the recirculation spray is given as $77^{\circ} \mathrm{C}$. According to the design of the system, the spray mass flow rates in the direct and the recirculation spray modes are 814 and 1050 ton per hour, respectively [3].

2.2. Physics Model. In GASFLOW two approaches are provided for two-phase flow simulation [4]. In the case that the spray model is not activated, the homogeneous equilibrium approach is applied automatically, which assumes the liquid and gas phases are in both thermodynamic and mechanical equilibrium. Because the containment spray brings strong transient and thermodynamic non-equilibrium, in order to more exactly simulate the interaction between the liquid and gas phases during the spray operation, GASFLOW offers another approach in which the thermodynamic nonequilibrium between liquid and gas phases is considered, but the difference of mechanical behavior between the liquid and gas phases is still neglected. The GASFLOW spray model has been validated with TOSQAN experiments and provided satisfactory predictions of the experiment data [5].

The spray simulation induces a much smaller time step size and increases the computation time by several times. Due to heavy time consumption in the spray simulation, turbulence model is not used in all the cases because the computational cost becomes unacceptable while using the turbulence model. According to the experience from Karlsruhe Research Center (FZK), GASFLOW predicts nearly the same flow field and vortex formation with and without turbulent models in a coarse grid [6], such as the grid used in containment geometry model. The heat conduction inside the structures is simulated in a one-dimensional approach. The PARs installed in the containment were simulated with the standard model provided by the GASFLOW code.

2.3. Accident Scenario. The hydrogen/water source term for this analysis was obtained by scaling from GKN surge line LBLOCA source term reported in [6], as indicated in Figure 3. The break is located in the lower part of the SG tower which is next to the pressurizer room. At the

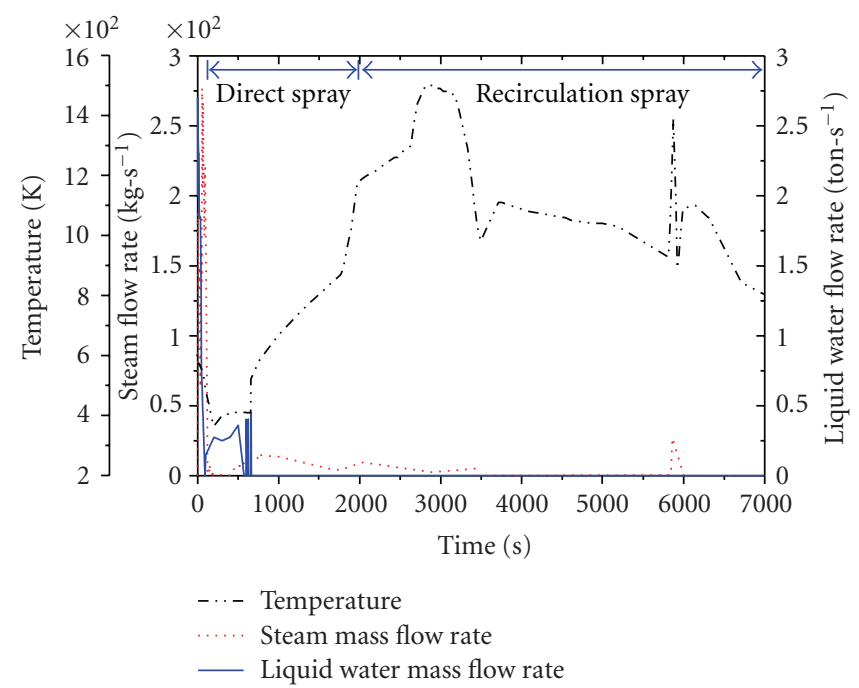

(a) Water release rate and temperature

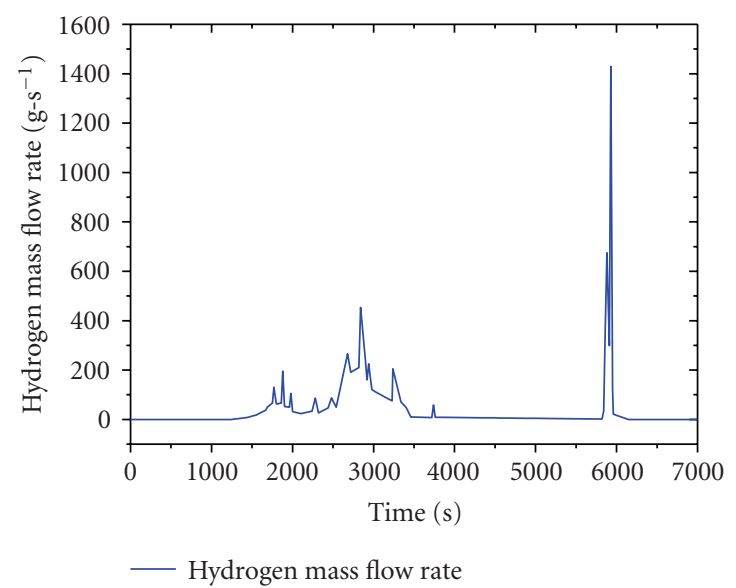

(b) Hydrogen release rate

FIGURE 3: Source term and spray activation.

beginning, a large amount of saturated water is discharged to the containment. The water discharge flow rate decays promptly due to the limited coolant inventory in the primary loop. Water in the reactor core is heated by the decay heat which rises the water temperature to superheated condition after the saturated release period. At about 1400 seconds, hydrogen generation and release starts. About $270 \mathrm{~kg}$ hydrogen is released into the containment during the first 7000 s.seconds At 5930 seconds, hydrogen release peak rate is produced due to an enhancement of steam/zirconium reaction after the failure of the core support. Besides the source term, Figure 3(a) indicates also the two spray periods. The start time of direct spray is determined according to the pressure variation obtained in the base case. In about 60 seconds, the pressure in the containment reaches the threshold value and the direct spray starts.

2.4. Thermal Hydraulics. At the beginning of the LBLOCA accident, along with a heavy discharge of water to the containment, the pressure and gas temperature inside 


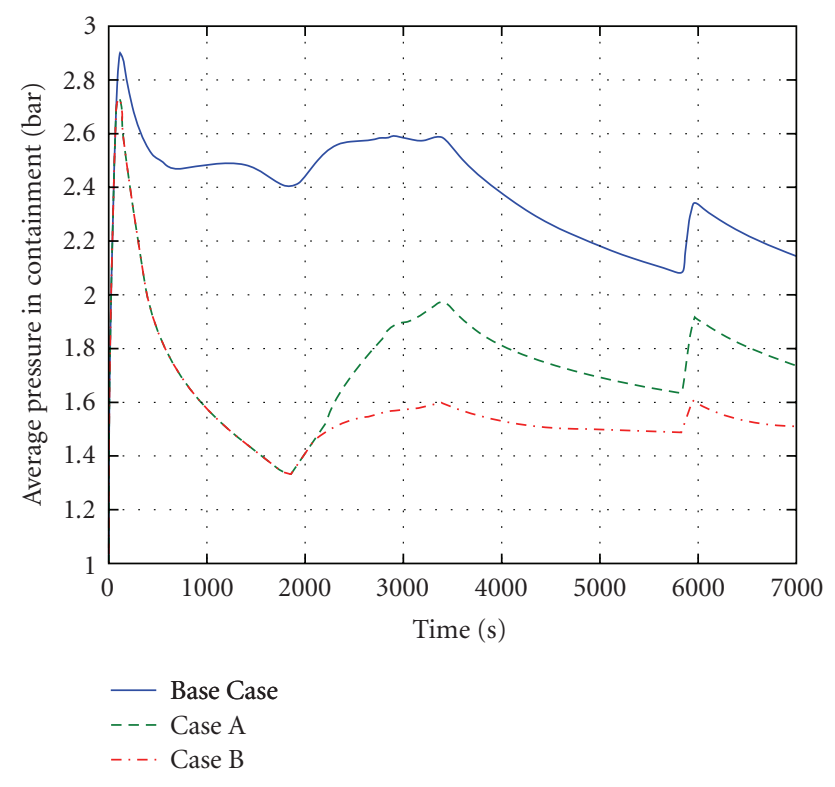

Figure 4: Pressure variation in three cases.

the containment increase sharply. The hot steam mixes promptly and intensively with the atmosphere and soon spreads through the containment, which results in strong condensation on the structure surface. The condensation helps delaying the containment pressurization in the severe accident. Figures 4 and 5 compare the pressure and gas temperature variation in three cases. In all the cases, a sharp pressure and temperature increase occurs and the pressure reaches the maximum at the beginning of the blowdown. Although different approaches are utilized to deal with the two phases in the base case and spray cases, large discrepancies of the global behavior are not observed before the spray activation in the cases. For the base case, the pressure and gas temperature variation inside the containment is mainly affected by the water injection and the condensation on the structure. The computation result shows that, with the current source term, the pressure does not exceed the design value. In Case A and B, the pressure and the gas temperature inside the containment show lower peak values and decrease fast after the activation of the direct spray until its shutdown. Without the circulation spray, the pressure and gas temperature rebounds to high level in Case A because the hot steam continues being discharged after the shutdown of the direct spray. In Case B, the recirculation spray holds the pressure and the gas temperature slightly higher than the lowest value induced by the direct spray.

Figure 6 presents the bulk evaporation rate in the containment during all the cases. The direct containment spray introduces intensive bulk condensation (negative value in Figure 6). Conversely, the recirculation spray brings bulk evaporation. The evaporation of the spray water is beneficial with respect to hydrogen risk because it increases the steam concentration and builds up an inertial atmosphere which resists the hydrogen combustion. With respect to hydrogen risk, the outlet temperature of the recirculation spray should be optimized to enhance the evaporation of the spray water.

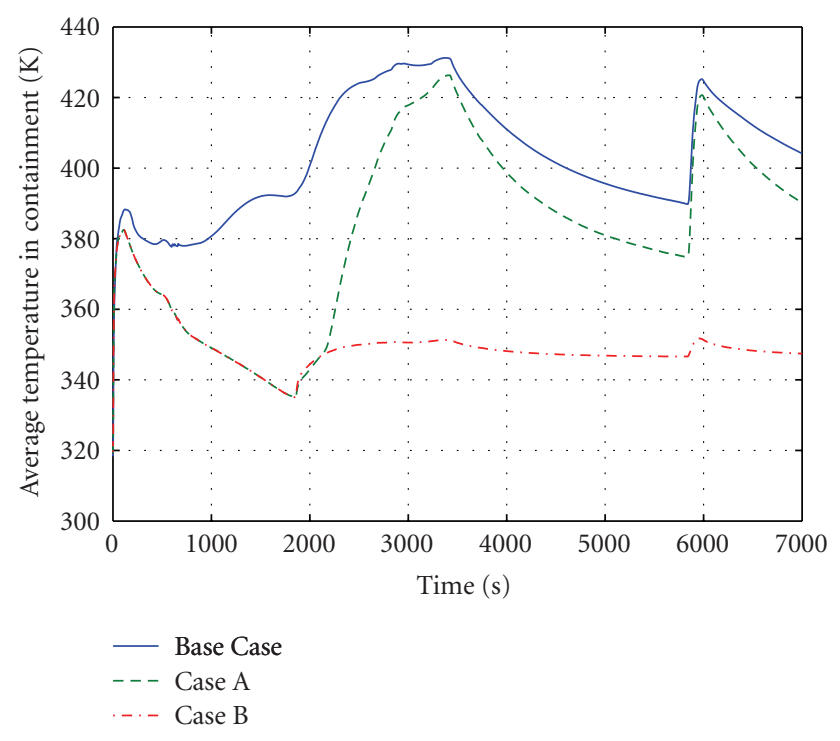

FIGURE 5: Average temperature variation.

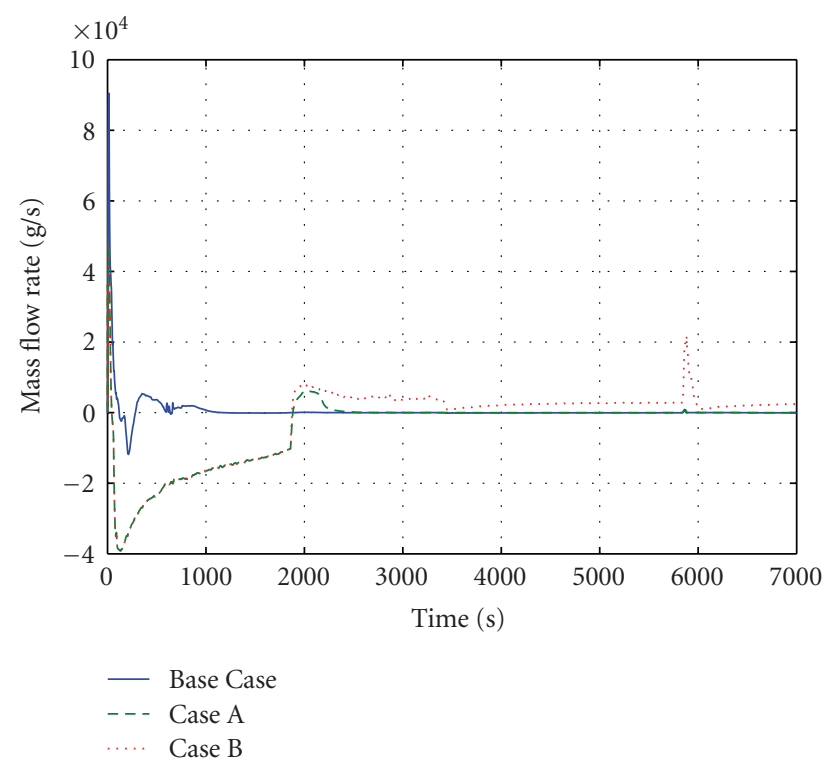

Figure 6: Bulk evaporation rate in all cases.

Figure 7 gives the total condensation rate on the structure surface. During the direct spray phase in the Cases A and B, the condensation on the structures is at a much lower rate than that in the base case due to the enhancement of the bulk condensation which reduces both the gas temperature and steam concentration. The condensation on the structures is one of the major ways in which heat is transferred from the atmosphere to the structures. Hence, a low condensation rate leads to a low heat transfer rate from the gas to the structures, as indicated in Figure 8. However, during the recirculation spray in Case $\mathrm{B}$, the condensation on the structures is observed to be at a similar rate with that in the base case. In Case B, both the bulk evaporation and the 


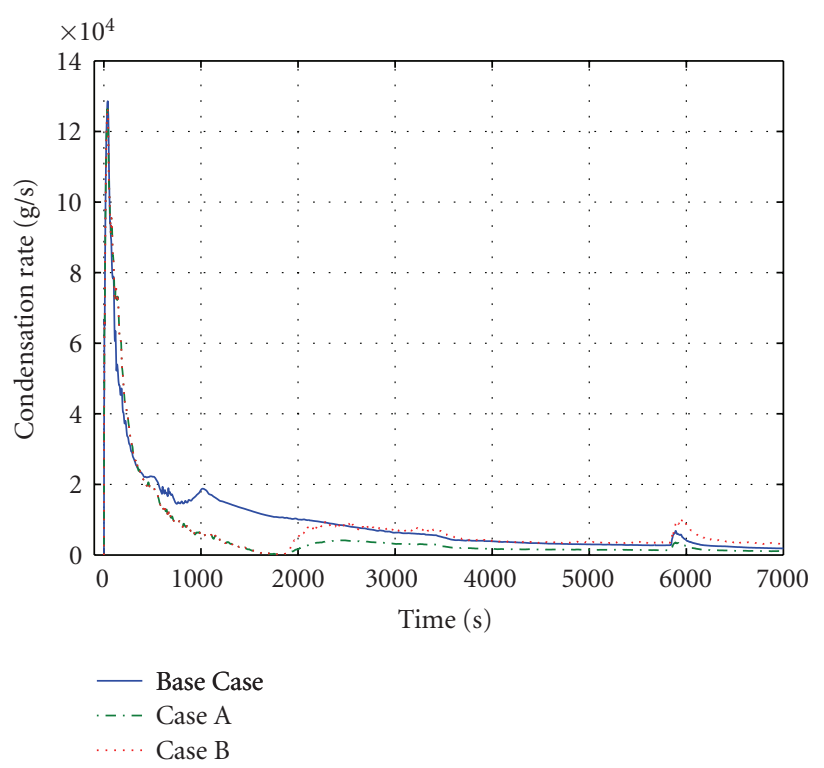

Figure 7: Total condensation rate on structure surfaces.

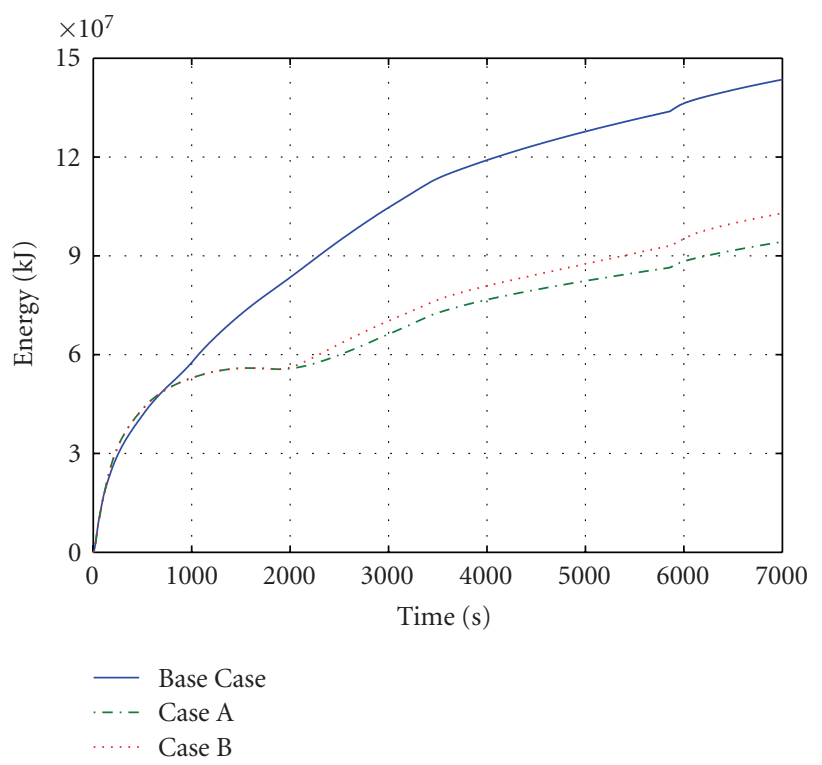

FIGURE 8: Energy absorption by structures.

surface condensation are enhanced by the recirculation spray. The evaporation of spray water takes away a lot of sensible heat from the atmosphere and contributes to stabilize the gas temperature inside the containment. Comparing both the bulk evaporation rate and the surface condensation rate in the Cases A and B shows that the recirculation spray generally increases the steam inventory inside the containment, which reduces the hydrogen combustion or detonation risk. Hence, it can be concluded that besides controlling the pressure and gas temperature inside the containment, the recirculation spray can build a comparatively inertial atmosphere for hydrogen.
2.5. Flow Field. Figure 9 presents the flow fields during the heavy hydrogen release period in all the cases. In the base case and Case A, similar flow fields are observed. Because the released gas is hydrogen-rich and of high temperature and low density, a buoyancy jet flow forms above the SG tower in which the break is located. The jet flow is reflected by the dome and flows downward into the other side of the containment. A large-scale vortex can be observed in the upper space. The condensation and the convection heat transfer on the structures remove the steam and heat from the atmosphere, the gas near the structures is heavier than the gas in the bulk. Hence, the downward flow can be observed near the structure surfaces. During the hydrogen release peak in the base case and Case A, the magnitude of velocity is generally less than $0.5 \mathrm{~m} / \mathrm{s}$. A chaotic flow field is induced by the recirculation spray, as indicated in Figure 9(c). The flow velocities in Case B are much higher than that in the other two cases. As mentioned in Section 2.2, GASFLOW spray model uses the mechanical equilibrium assumption while dealing with the two-phase flow. Actually, the heavy liquid phase is more inclined to drop down than the gas phase. The assumption inevitably leads to an artificial flow. In the actual situation, mechanical interaction between the liquid and gas phases could lead to a flow pattern different from the obtained results.

2.6. Hydrogen Recombination, Hydrogen and Steam Distribution. In the analyzed scenario, the hydrogen release can be generally divided into two periods. The first period lasts from $1400 \mathrm{~s}$ to $3500 \mathrm{~s}$. In this period, the global hydrogen volume fraction in the containment reaches $3 \%$, but the flammable clouds (at hydrogen concentration above 4\%) rarely appear. Due to the hydrogen-oxygen recombination, the hydrogen concentration can be reduced to less than 3\% before the second hydrogen release period starts. During the second period, the hydrogen release is discontinuous. However, intensive hydrogen release between 5900 and 6000 s could lead to extremely high local hydrogen concentration. Figure 10 presents snapshots of hydrogen and steam clouds right after the hydrogen release peak. A clear gas stratification can be observed in both the base case and Case A. Hydrogen-rich clouds are enveloped by steam-rich clouds during most of the time, which provides an inertial atmosphere for hydrogen and prevents early hydrogen combustion. The combustible hydrogen cloud in Case A is of the biggest size among the three cases. Compared with the base case, the steam concentration is low in the spray cases. Due to strong mixing induced by the recirculation spray, hydrogen stratification is not observed in Case B, as shown in Figure 10(c). Hence, the direct spray reduces the steam volume fraction and increases the hydrogen volume fraction, while the recirculation spray does not lead to an increase of hydrogen concentration but prevents the hydrogen concentration stratification.

In the Siemens PAR correlations [4], the recombination rate depends on the pressure and inlet hydrogen and oxygen concentration. Although the pressure is very different in the 


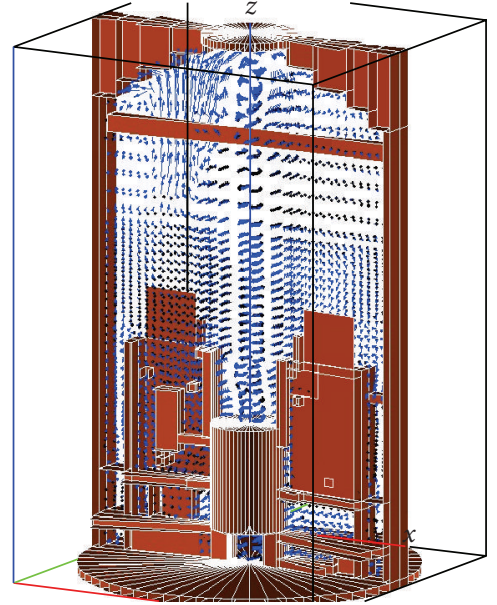

(a) base case $t=5910 \mathrm{~s}$

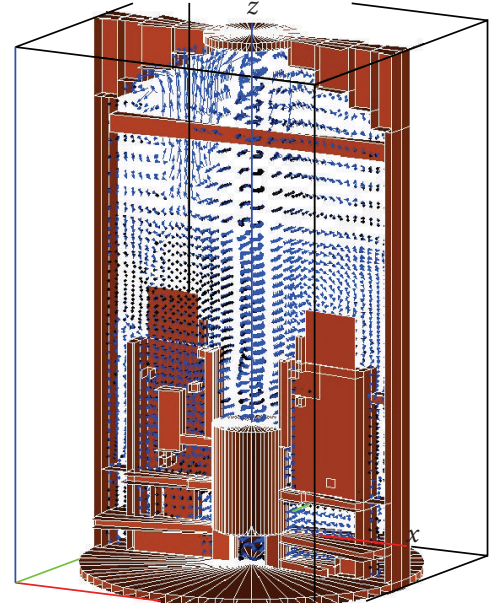

(b) Case A $t=5910 \mathrm{~s}$

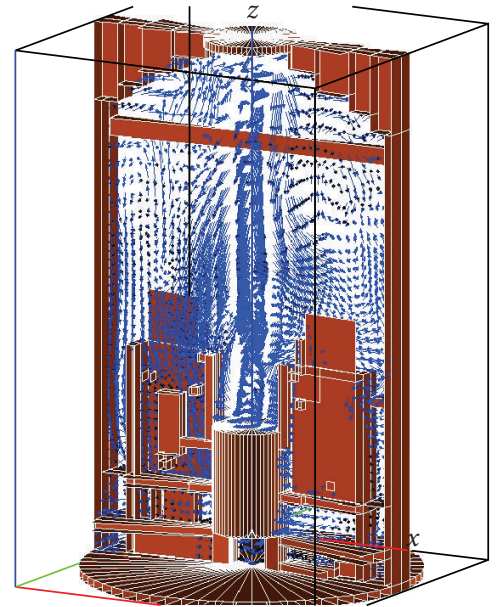

(c) Case B $t=5910 \mathrm{~s}$

FIGURE 9: Flow fields during the hydrogen release peak.

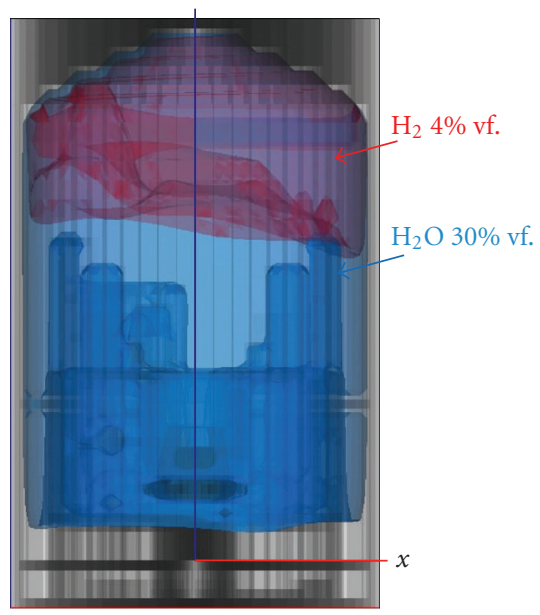

(a) base case at $5960 \mathrm{~s}$

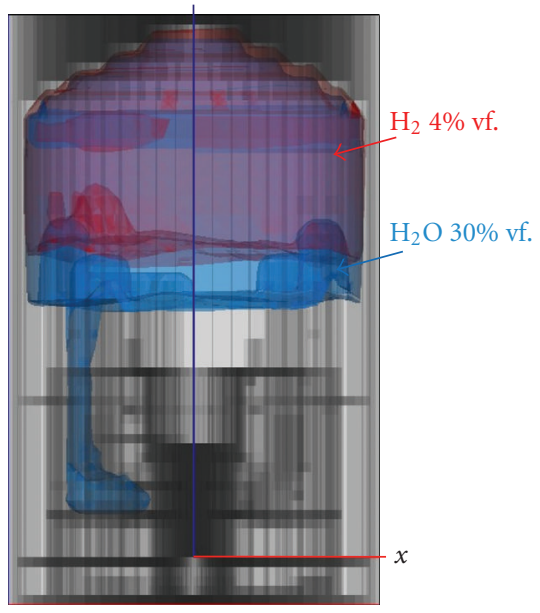

(b) Case A at $5960 \mathrm{~s}$

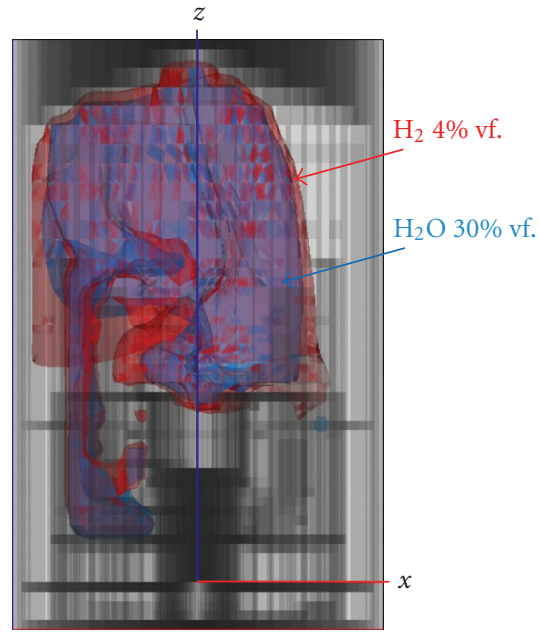

(c) Case B at $5950 \mathrm{~s}$

Figure 10: Hydrogen and steam clouds at the moment when hydrogen release reaches peak value.

analyzed cases, as mentioned in Section 2.4, the total recombination rate of 22 PARs does not show great difference in all the cases, as shown in Figure 11. Generally, the evolution of the recombination rate is in the same trend. Following the hydrogen release into the containment, the recombiners start up when the inlet hydrogen concentration reaches the startup threshold ( 2 vol. \%). Along with the hydrogen accumulation in the containment, the recombination rate ascends. At the end of the first hydrogen release period, the recombination is at an almost stable rate. During the second period, when the hydrogen release is discontinuous and at a quite low rate, the recombination rate reduces smoothly and slowly. The oscillation of recombination rate is observed in this period in Case B because strong flow caused by the spray brings the strong variation of hydrogen concentration at the inlet of PARs. After $5900 \mathrm{~s}$, the spray cases show a higher hydrogen removal capability than the base case due to higher global hydrogen concentration. In GASFLOW, the volume flow rate through the PAR is deduced from the recombination rate obtained from Siemens correlations. In this case, the recombination rate is affected only by the gas species concentration and pressure at the inlet of PAR. However, BMC Zx test results [7] suggest an increase of the volume flow rate through PARs and recombination rate due to the spray.

In order to indicate the characteristics of the hydrogen mixture and the hydrogen combustion risk in the containment, the volume of sigma cloud is involved in this paper. The sigma cloud is a volume of the hydrogen-air-steam mixture with a combustion expansion ratio higher than the critical value obtained from experimental data [8]. Flame acceleration could occur in a sigma cloud. Figure 12 presents 


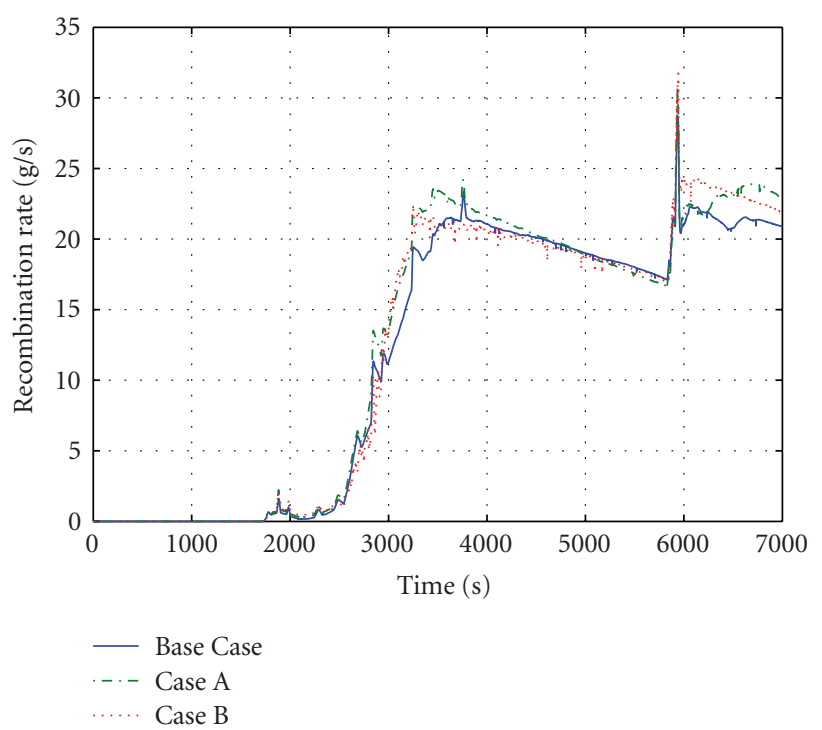

FIgURE 11: Total recombination rate of 22 PARs.

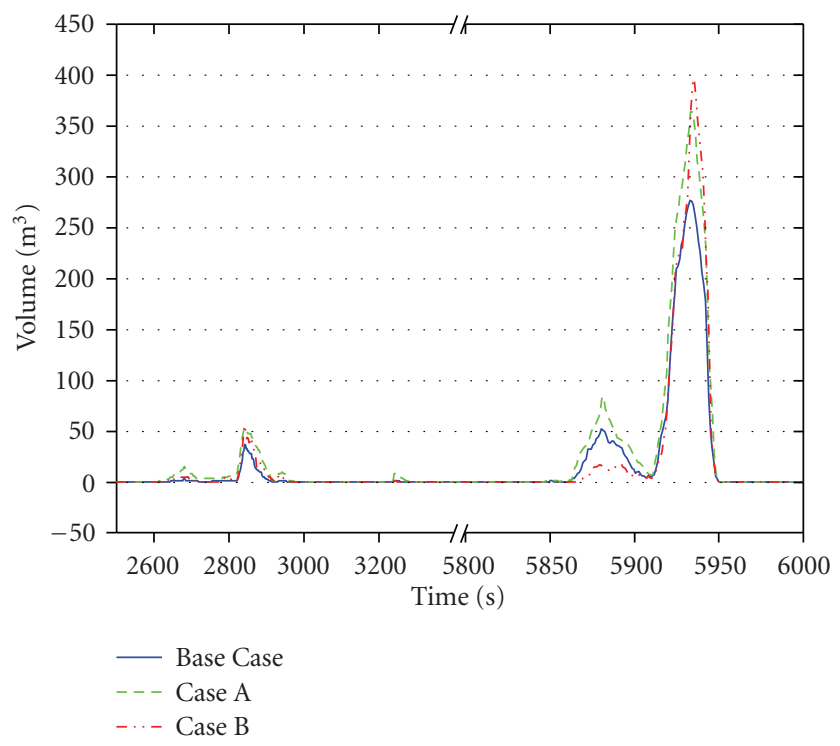

FIgURE 12: Total volume of sigma clouds.

the evolution of total sigma volume inside the containment in three cases. During the analyzed accident, a sigma volume peak can be observed in all the cases. And the maximum sigma volume in the spray cases is larger than that in the base case, while the maximum sigma volume in the Cases $\mathrm{A}$ and B is not quite different. However, if compared carefully, it can be found that the sigma volume in Case A shows to be larger than that induced by Case B at the second peak, and smaller at the third peak. It implies that the recirculation spray reduces the hydrogen risk during the slow hydrogen release period, but can slightly increase the local hydrogen concentration around the hydrogen source and lead to a larger sigma volume at the moment when the peak hydrogen release rate occurs.
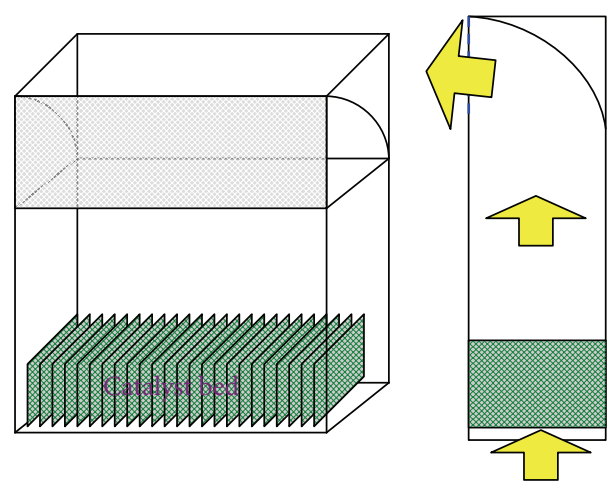

FIGURE 13: Schematic of a typical PAR [9].

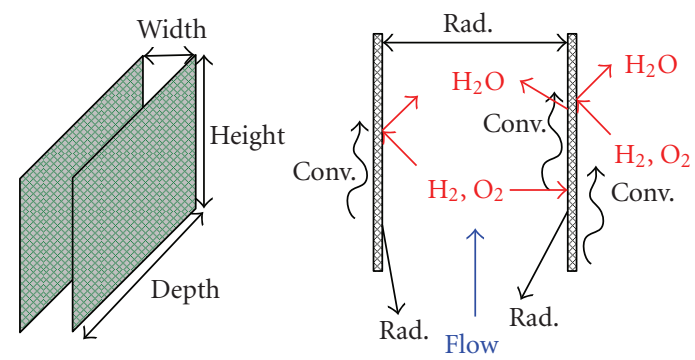

FIgURE 14: Physics phenomena in the catalyst flow channel [10].

\section{Recombiner CFD Model}

3.1. Passive Autocatalytic Recombiner. A passive autocatalytic recombiner consists of a vertical channel and a stack equipped with a catalyst bed in the lower part, as presented in Figure 13. In the case of severe accidents, the catalyst is in contact with the gas mixture of the containment. Hydrogen reacts with oxygen at the catalyst surface and generates steam, as indicated in Figure 14. The reaction heat released at the catalyst surface causes a buoyancy-induced flow which increases the inflow rate and thereby feeding the catalyst with a larger amount of hydrogen that ensures high efficiency of recombination. The buoyancy-driven circulation ensures a continuous gas supply to the PAR [2]. The catalyst sheets can be heated up to $900 \mathrm{~K}$ or even higher; so, considerable amount of heat is also transferred from the catalyst to the environment by heat radiation.

Left in Figure 14 shows a typical channel between two catalyst sheets. For small and medium recombiners of Siemens type, both height and depth are about $15 \mathrm{~cm}$. The width of flow channel is less than $1 \mathrm{~cm}$. In the PAR, the gas velocity, $u$, is in the magnitude of $1 \mathrm{~m} / \mathrm{s}$. The gas temperature could vary from $300 \mathrm{~K}$ to $700 \mathrm{~K}$. Assuming the gas in the PAR is dry air, the Reynolds number of the flow between the catalyst sheets is $\operatorname{Re}=2 u d / v=400 \sim 1250$. The flow is considered as a laminar flow in the channel.

3.2. Model Development. A two-dimensional PAR model is developed to simulate the flow in the channel, the heat transfer between the catalyst sheet and gas flow, the heat 


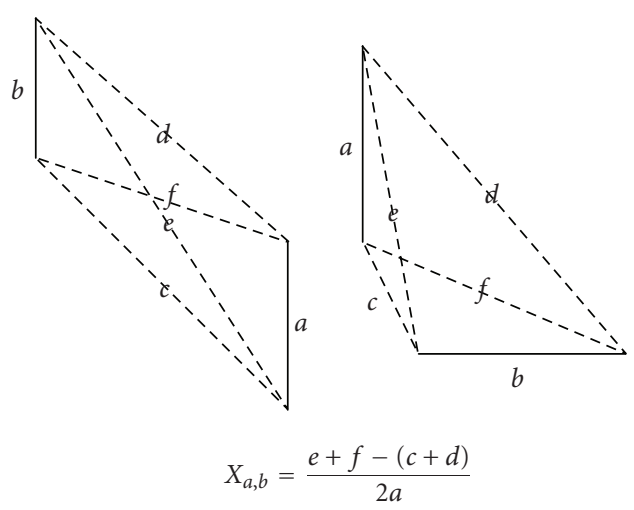

FIGURE 15: View factor of parallel and perpendicular plates.

conduction in the catalyst sheet and the chemical reaction on the catalyst surface. The variation of flow velocity, temperature and gas concentration in the depth direction is then neglected. The continuity equation, Navier-Stokes equation, and energy equation are coupled and solved with the SIMPLE algorithm. The Boussinesq assumption is applied to consider the buoyancy caused by heatingup. Since the flow is laminar, no turbulence model is utilized in the present model. For the radiation heat transfer, the emissivity and absorption ratios of the catalyst sheet are assumed to be one. The view factor can be easily obtained for the parallel and perpendicular plates in a two-dimensional model, as indicated in Figure 15. An environment temperature is assigned at the inlet and outlet of the channel to calculate the radiation heat transfer between the catalyst and the environment. The effect of steam in the heat radiation is currently not considered in this model. In the catalyst plate two-dimensional heat conduction is simulated. It was observed that the temperature difference can be neglected in the normal direction of catalyst plate surface. It can be concluded that one-dimensional heat conduction will be enough.

Besides the basic equations, the concentration equations (1) are solved for all the gas species except for nitrogen

$$
\rho u \frac{\partial c_{i}}{\partial x}+\rho v \frac{\partial c_{i}}{\partial y}=\rho D_{i}\left(\frac{\partial^{2} c_{i}}{\partial x^{2}}+\frac{\partial^{2} c_{i}}{\partial y^{2}}\right)+S_{\rho, i} .
$$

A one-step reaction model developed by Ikeda et al. [11] is applied to simulate the chemical reaction on the catalyst surface

$$
\mathrm{H}_{2}+\frac{1}{2} \mathrm{O}_{2} \longrightarrow \mathrm{H}_{2} \mathrm{O}
$$

with

$$
\dot{R}=14 \phi_{\mathrm{H}_{2}} \exp \left(-\frac{3580}{R \cdot T}\right) .
$$

In (3), the gas temperature in the cell next to the catalyst surface is applied in order to avoid an extremely high reaction rate. Based on the reaction rate obtained from (3), the source term for the energy and species equation can be easily calculated.

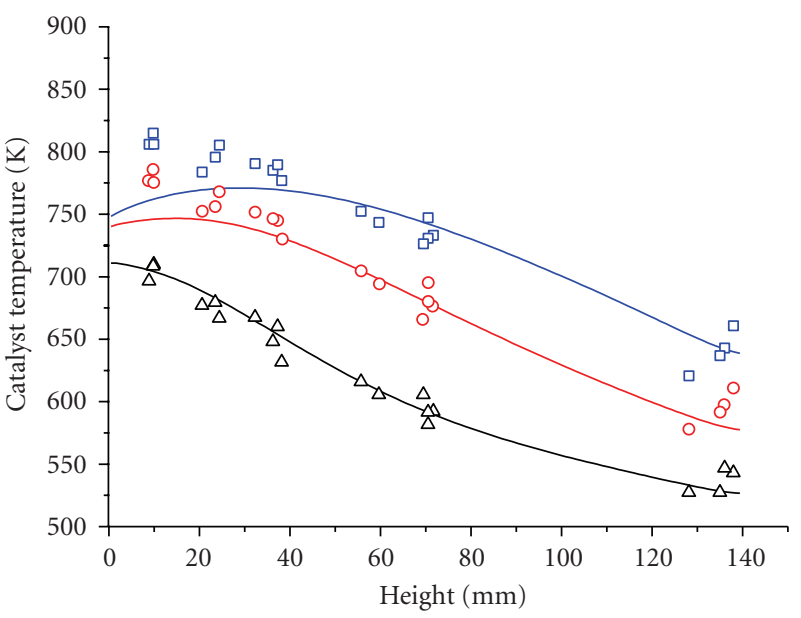

$$
\begin{aligned}
& \Delta \text { Inlet vel. }=0.25 \mathrm{~m} / \mathrm{s}(\text { exp. }) \quad \text { - Inlet vel. }=0.25 \mathrm{~m} / \mathrm{s}(\text { cal. }) \\
& \circ \text { Inlet vel. }=0.5 \mathrm{~m} / \mathrm{s}(\text { exp. }) \quad \text { Inlet vel. }=0.5 \mathrm{~m} / \mathrm{s}(\text { cal. }) \\
& \square \text { Inlet vel. }=0.8 \mathrm{~m} / \mathrm{s}(\text { exp. }) \quad \text { - Inlet vel. }=0.8 \mathrm{~m} / \mathrm{s}(\text { cal. })
\end{aligned}
$$

Figure 16: Catalyst temperature, model prediction versus experiment.

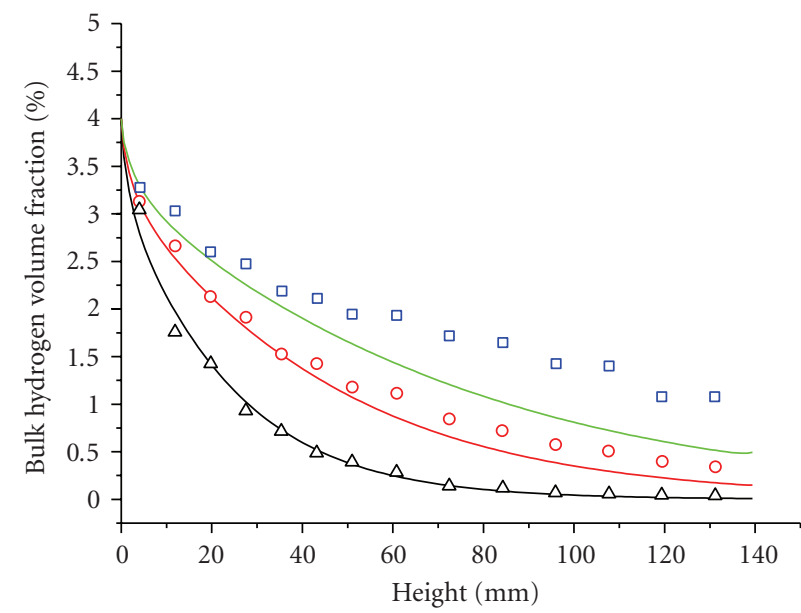

$$
\begin{aligned}
& \Delta \text { Inlet vel. }=0.25 \mathrm{~m} / \mathrm{s}(\text { exp. })-\text { Inlet vel. }=0.25 \mathrm{~m} / \mathrm{s}(\text { cal. }) \\
& \text { ○ Inlet vel. }=0.5 \mathrm{~m} / \mathrm{s} \text { (exp.) — Inlet vel. }=0.5 \mathrm{~m} / \mathrm{s} \text { (cal.) } \\
& \text { 口 Inlet vel. }=0.8 \mathrm{~m} / \mathrm{s}(\text { exp. })-\text { Inlet vel. }=0.8 \mathrm{~m} / \mathrm{s}(\mathrm{cal} \text {.) }
\end{aligned}
$$

Figure 17: Average hydrogen concentration in the flow channel, model prediction versus experiment.

3.3. Model Validation. The REKO-3 experiment results [9] are utilized to validate the model. REKO-3 experiments are conducted by Forschungszentrum Juelich, Germany. The test section of the REKO-3 facility consists of four catalyst sheets forming three flow channels. The facility provides the measurement of catalyst temperature and gas concentration at different heights. Experiment results are obtained at different inlet velocities.

Figures 16 and 17 compare the numerical results with the experimental data under three inlet velocities. The hydrogen volume fraction at the inlet is $4 \%$ in all cases. Among all 
the cases, the model gives the best prediction at lowest inlet velocity $(0.25 \mathrm{~m} / \mathrm{s})$. A clear deviation of the catalyst temperature near the inlet is observed for other two cases. An increasing catalyst temperature leads to a significant heat loss from the catalyst to the environment, especially for the inlet neighborhood where both the temperature and the view factors to the environment are high. The deviation of the catalyst temperature can be minimized by optimizing the environment temperature and by setting the exact emissivity and absorption ratio of the catalyst material. In the cases where the inlet velocity is $0.5 \mathrm{~m} / \mathrm{s}$ and $0.8 \mathrm{~m} / \mathrm{s}$, an overestimation of recombination by the model is observed. This could be caused by overestimating the chemical reaction rate on the catalyst or by overpredicting the mass transfer to the catalyst. Generally, the model gives satisfactory prediction of the experiment results.

\section{Conclusion}

The hydrogen analysis with the CFD code GASFLOW is conducted to investigate the effect of spray modes on hydrogen risk in the Qinshan-II NPP containment during a large break loss of coolant accident (LBLOCA). The direct spray sharply depresses the pressure and temperature in the containment and reduces the heat transfer from the atmosphere to the structures. However, the direct spray mode (case A) is still not capable of controling the pressure and gas temperature during the accident due to the strong release of hot steam after the shutdown of the direct spray. A considerable evaporation of the recirculation spray water is observed. Compared with Case A, the enhancement of the condensation on the structures is also observed during the recirculation spray (case $\mathrm{B}$ ). Because the evaporation induced by the recirculation spray is generally stronger than the enhancement of surface condensation, the steam inventory inside the containment is increased due to the recirculation. During the hydrogen release peak, a chaotic mixing flow field is produced by the recirculation spray, while a regular natural convection flow forms in the other two cases. From the aspect of hydrogen safety, the direct spray increases the global hydrogen concentration and the maximum sigma volume, but does not prevent the stratification. The recirculation spray does not increase the global hydrogen concentration inside the containment and promotes mixing, but can increase the local hydrogen concentration near the hydrogen release source. The effects of the containment spray on the PAR performance are found to be minor.

A CFD recombiner model is developed in order to provide more detailed insights into the process along the catalyst sheets. The model is validated with the data from the REKO-3 experiment [9] and gives satisfactory prediction. Further work is needed to develop a full recombiner model by incorporating the chimney part. For implementation of the CFD PAR model in containment analysis, appropriate boundary conditions are needed at the inlet of the PAR.

\section{Nomenclature}

$c_{i}$ : Mass fraction of $i$ th gas species

$D_{i}$ : Diffusion coefficient of $i$ th gas species, $\mathrm{m}^{2} / \mathrm{s}$

$d$ : Gap width between two catalyst plates, $\mathrm{m}$

$R: \quad$ Universal gas constant, $\mathrm{J} /(\mathrm{mol}-\mathrm{K})$

$\dot{R}: \quad$ Reaction rate, $\mathrm{mol} /\left(\mathrm{m}^{3}-\mathrm{s}\right)$

Re: Reynolds number

$S_{\rho, i}:$ Mass source term of $i$ th gas species per unit volume, $\mathrm{kg} /\left(\mathrm{m}^{3}-\mathrm{s}\right)$

T: $\quad$ Temperature, $\mathrm{K}$

$u$ : Velocity in $x$ direction, $\mathrm{m} / \mathrm{s}$

$v$ : Velocity in $y$ direction, $\mathrm{m} / \mathrm{s}$

$\rho: \quad$ Gas density, $\mathrm{kg} / \mathrm{m}^{3}$

$\phi_{\mathrm{H}_{2}}$ : Hydrogen molecular concentration, $\mathrm{mol} / \mathrm{m}^{3}$

$v: \quad$ Kinetic viscosity, $\mathrm{m}^{2} / \mathrm{s}$

\section{Acknowledgments}

The authors would like to thank National Basic Research Program of China (no.2007CB209800) for providing the financial support for this study. The authors would also like to thank the experts from FZK GASFLOW group for their kind help.

\section{References}

[1] J. R. Travis, J. W. Spore, P. Royl, et al., "GASFLOW: a computational fluid dynamics code for gases, aerosols, and combustion," Vol. 2, User's Manual, LA-13357-MS, FZKA5994, October 1998.

[2] E. Bachellerie, F. Arnould, M. Auglaire, et al., "Generic approach for designing and implementing a passive autocatalytic recombiner PAR-system in nuclear power plant containments," Nuclear Engineering and Design, vol. 221, no. 1-3, pp. 151-165, 2003.

[3] T. Zhang, et al., "Operation manual of nuclear power plant," Nuclear Power Qinshan Joint Venture Company Ltd., 2005.

[4] J. R. Travis, J. W. Spore, P. Royl, et al., "GASFLOW: a computational fluid dynamics code for gases, aerosols, and combustion," Vol. 1, Theory Manual, LA-13357-MS, FZKA5994, October 1998.

[5] J. Malet, L. Blumenfeld, S. Arndt, et al., "Sprays in containment: final results of the sarnet spray benchmark," in Proceedings of the 3rd European Review Meeting on Severe Accident Research (ERMSAR '08), pp. 1-19, Nessebar, Bulgaria, September 2008.

[6] P. Royl, H. Rochholz, W. Breitung, J. R. Travis, and G. Necker, "Analysis of steam and hydrogen distributions with PAR mitigation in NPP containments," Nuclear Engineering and Design, vol. 202, no. 2-3, pp. 231-248, 2000.

[7] OECD/NEA, "SOAR on Containment Thermalhydraulics and Hydrogen Distribution," Tech. Rep. CSNI-R99-16, OECD Nuclear Energy Agency, Nuclear Safety, Paris, France, June 1999.

[8] S. B. Dorofeev, M. Kutznetsov, V. Alekseev, A. A. Efimenko, and W. Breitung, "Evaluation of limits for effective flame acceleration in hydrogen mixtures," Report IAE-6150/3, Kurchatov Institute, Moscow, Russia, 1999. 
[9] E. A. Reinecke, J. Boehm, P. Drinovac, S. Struth, and I. M. Tragsdorf, "Numerical and experimental investigations on catalytic recombiners," in Proceedings of the 13th International Conference on Nuclear Engineering (ICONE '05), Beijing, China, May 2005, ICONE 13-50267.

[10] M. Heitsch, "Fluid dynamic analysis of a catalytic recombiner to remove hydrogen," Nuclear Engineering and Design, vol. 201, no. 1, pp. 1-10, 2000.

[11] H. Ikeda, P. A. Libby, F. A. Williams, and J. Sato, "Catalytic combustion of hydrogen-air mixtures in stagnation flows," Combustion and Flame, vol. 93, no. 1-2, pp. 138-148, 1993. 

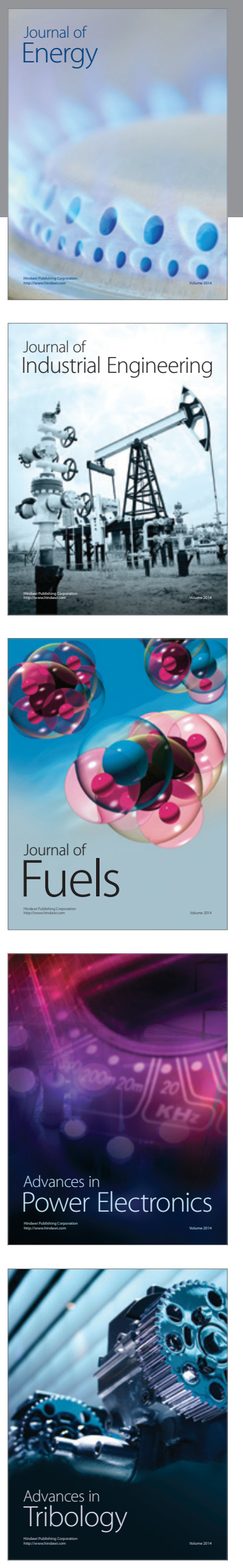
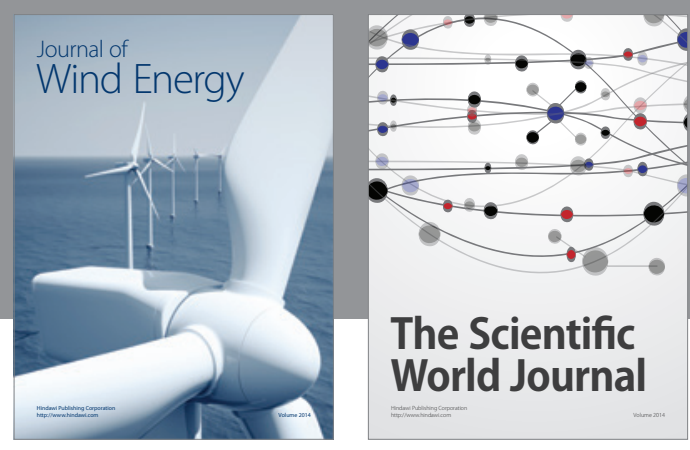

The Scientific World Journal

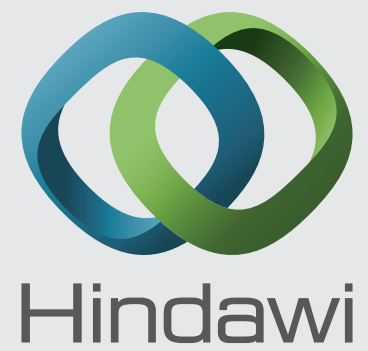

Submit your manuscripts at http://www.hindawi.com
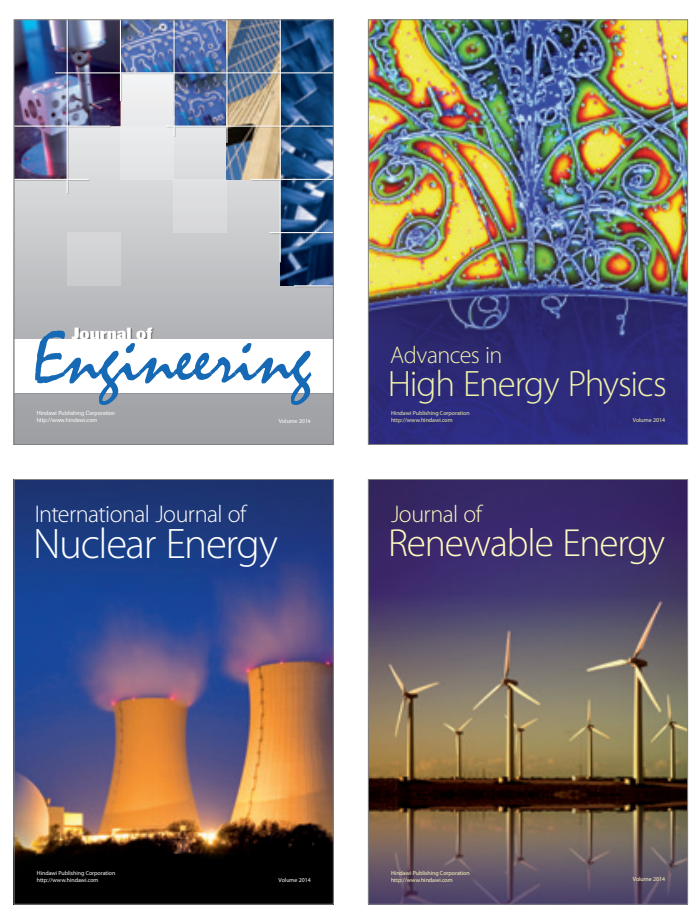

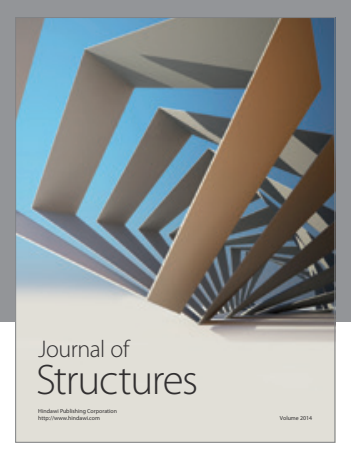

Rotating
Mechinery
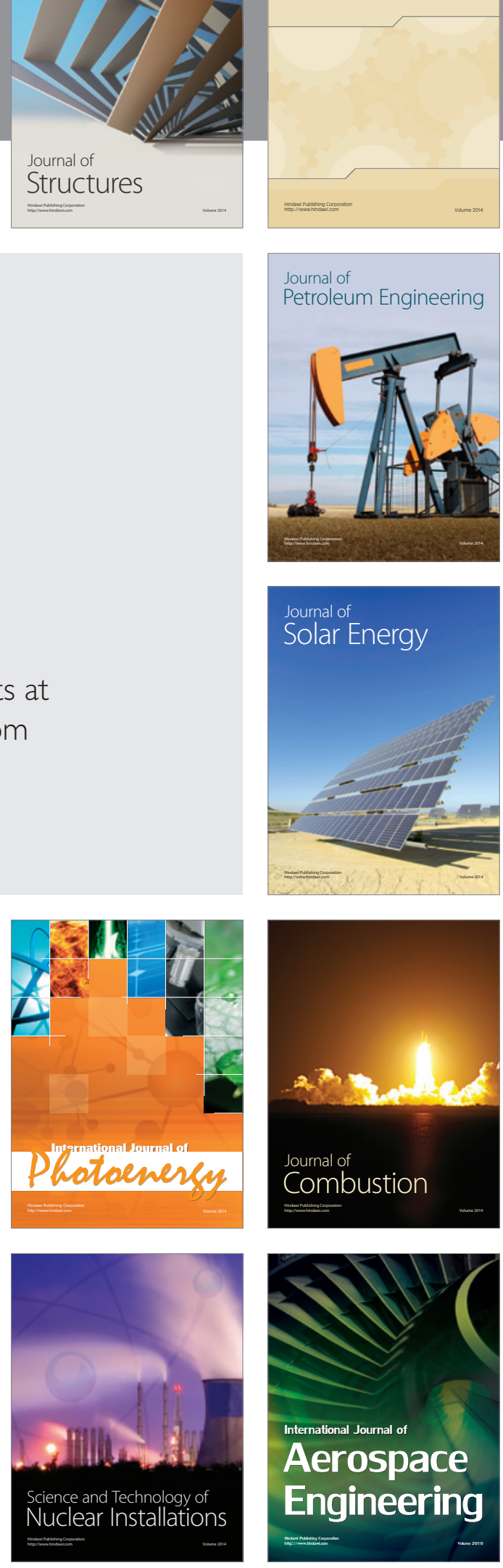